\title{
Effect of allergic phenotype on treatment response to inhaled bronchodilators with or without inhaled corticosteroids in patients with COPD
}

\author{
This article was published in the following Dove Press journal: \\ International journal of COPD \\ 31 July 2017 \\ Number of times this article has been viewed
}

\author{
Shih-Lung Cheng ${ }^{1,2}$ \\ Hsu Hui Wang' \\ Ching-Hsiung Lin $^{3-5}$ \\ 'Department of Internal Medicine, \\ Far Eastern Memorial Hospital, \\ Taipei, ${ }^{2}$ Department of Chemical \\ Engineering and Materials Science, \\ Yuan Ze University, Taoyuan, ${ }^{3}$ Division \\ of Chest Medicine, Department of \\ Internal Medicine, Changhua Christian \\ Hospital, Changhua, ${ }^{4}$ Department of \\ Respiratory Care, College of Health \\ Sciences, Chang Jung Christian \\ University, Tainan, ${ }^{5}$ School of Medicine, \\ Chung Shan Medical University, \\ Taichung, Taiwan
}

\begin{abstract}
Background: Chronic obstructive pulmonary disease (COPD) is a heterogeneous disorder encompassing different phenotypes with different responses to treatment. The present 1-year, two-center hospital-based study investigated whether the plasma immunoglobulin E (IgE) level and/or eosinophil cell count could be used as biomarkers to stratify patients with COPD according to predicted responses to inhaled corticosteroids (ICS)-based therapy.
\end{abstract}

Methods: A hospital-data based cohort study of COPD patients treated at two territory hospital centers was conducted for 1 year. Allergic biomarkers, including blood eosinophil counts and IgE levels, were assessed at baseline. Lung function parameters, including forced expiratory volume in 1 second $\left(\mathrm{FEV}_{1}\right)$, forced vital capacity (FVC), and the COPD Assessment Test (CAT), were also evaluated. The frequencies of acute exacerbation (AE) and pneumonia were also measured. Eosinophilia and a high IgE level were defined as $>3 \%$ and $173 \mathrm{IU} / \mathrm{mL}$, respectively.

Results: A total of 304 patients were included. Among patients with eosinophilia and high IgE levels, ICS-based therapy was associated with significant improvements in FEV, $\mathrm{FVC}$, and CAT scores, compared with bronchodilator (BD) therapy $(P \leq 0.042)$. ICS-based therapy was also associated with a significantly lower incidence of AE vs BD-based therapy $(11.7 \%$ vs $24.1 \%$; $P<0.008)$. Among patients with only eosinophilia, ICS-based therapy yielded significantly better CAT score results vs BD-based treatment ( 7 vs $13 ; P=0.032$ ). A receiver operating characteristic curve analysis found that the combination of a high plasma IgE level and eosinophilia most sensitively and specifically identified patients who would benefit from the addition of ICS to BD therapy.

Conclusion: Our findings support the use of blood eosinophil cell counts plus IgE levels as predictive biomarkers of the ICS response in certain patients with COPD. Both biomarkers could potentially be used to stratify COPD patients regarding ICS-based therapy.

Keywords: chronic obstructive respiratory disease, COPD, allergy, bronchodilators, corticosteroids, exacerbation, pulmonary function, COPD Assessment Test

\section{Introduction}

Chronic obstructive pulmonary disease (COPD) and asthma are characterized by airflow obstruction. ${ }^{1,2}$ Despite this and other similarities, however, the two diseases have distinct characteristics. COPD is characterized by the presence of poorly reversible airway obstruction and is commonly associated with a history of tobacco smoking. ${ }^{3}$ The COPD-associated inflammatory milieu primarily comprises macrophages, neutrophils, and cytotoxic $\left(\mathrm{CD}^{+}\right) \mathrm{T}$ cells. ${ }^{3}$ By contrast, asthma airway obstruction is either totally
Division of Chest Medicine, Department of Internal Medicine, Changhua Christian Hospital, I 35 Nanxiao St, Changhua City, Changhua County 500, Taiwan

Tel +88647238595

Fax +88647228289

Email teddy@cch.org.tw 
or partially reversible, and this occurs spontaneously or in response to medical treatment. ${ }^{4}$ Additionally, the asthmaassociated inflammatory milieu is typified by the activation of mast cells and elevations in the numbers of activated eosinophils and natural killer cells and type $2 \mathrm{~T}$ helper $\left(\mathrm{CD}^{+}\right)$ cell-produced (Th2) cytokine levels. ${ }^{4}$ Additionally, patients with allergic asthma exhibit elevated total serum immunoglobulin E (IgE) and antigen-specific levels. ${ }^{5}$

Not all patients with COPD respond similarly to treatment, and the heterogeneity of COPD has become increasingly apparent. Several different existing COPD phenotypes describe the variability among individual patients with COPD with respect to clinically important parameters such as symptoms, exacerbations, treatment responses, disease progression, and mortality. ${ }^{6}$ To date, four phenotypes have been described: emphysema, chronic bronchitis, frequent exacerbators, and asthma-COPD overlap syndrome (ACOS)., Patients with ACOS, which affects approximately $15 \%-20 \%$ of those with COPD, exhibit features of both COPD and asthma. ${ }^{8-11}$ Patients with ACOS tend to be younger, have a shorter smoking history, and use more respiratory medication, compared to patients with COPD. ${ }^{12}$ The levels of $\operatorname{IgE}$ and antigen-specific $\operatorname{IgE}$ are higher among patients with ACOS than those with COPD. ${ }^{12}$ In addition, the presence of peripheral eosinophilia $(>300$ eosinophils $/ \mu \mathrm{L}$ or $>5 \%$ leukocytes) and a prior history of atopy are considered characteristics of ACOS. ${ }^{13}$ Traditionally, patients with the ACOS phenotype have been excluded from major clinical studies of asthma because of their smoking histories and from studies of COPD because of bronchodilator (BD)mediated reversibility., ${ }^{4,14}$ Frequent exacerbators are those patients with $\geq 2$ exacerbations per year, a presentation that is associated with poor prognosis. ${ }^{15-17}$ An elevated sputum eosinophil level ( $\geq 3 \%$ ) has been associated with exacerbations in up to $28 \%$ of patients with COPD. ${ }^{18,19}$ Increased serum eosinophilia is also present in approximately $30 \%$ of patients with stable COPD and may predict an increased risk of exacerbation. ${ }^{20}$

According to current concepts, master regulators within the airway epithelium, such as IL-33, increase the activity of Th2 cytokines in the airway and trigger a cascade of downstream events, including IgE-medicated hypersensitivity and effector cell (mast cells, eosinophils, and basophils) chemoattraction. ${ }^{21}$ Regarding asthma pathogenesis, the Global Initiative for Asthma (GINA) guideline recommendations suggest the use of inhaled corticosteroids (ICS) as the optimal treatment for these T helper cells. ${ }^{22}$ By contrast, the use of ICS treatment for COPD remains controversial. Although ICS reduce the risk of exacerbation in patients with COPD, ICS monotherapy less effectively improves lung function when compared with longacting BDs (long-acting $\beta$-agonists [LABAs]) and does not affect declines in lung function or mortality. ${ }^{23-26}$ In addition, the long-term use of ICS increases the risk of pneumonia. ${ }^{27}$ Current guidelines recommend the use of ICS in combination with LABAs for COPD patients with severe airflow limitations and frequent exacerbations despite the use of regular BD therapy. ${ }^{2}$ However, ICS are commonly used with LABAs for the clinical treatment of patients with mild-to-moderate COPD. ${ }^{28,29}$ The guidelines also recommend the avoidance of ICS monotherapy in patients with COPD.

Historically, treatment decisions have been based on the severity of airflow limitation. However, treatment approaches are shifting to an increased focus on clinical phenotype. ${ }^{30}$ The identification of biomarkers predictive of treatment responses in a COPD population comprising diverse phenotypes would yield significant clinical benefits. Several studies have found that patients with increased IgE levels exhibit increased responses to treatment when corticosteroids are added to BD therapy, compared to those without high IgE levels. ${ }^{4,31}$ Siva et al found that in patients with COPD who present with sputum eosinophilia (but not those without eosinophilia), ICS significantly reduce exacerbations. ${ }^{32}$ However, only a few studies have specifically investigated whether blood eosinophil cell counts or IgE levels could serve as biomarkers for identifying the subset of COPD patients who would benefit from the addition of ICS to BD therapy. ${ }^{33-38}$

Little is known about whether COPD patients with high IgE levels and/or eosinophilia would respond well to ICS therapy. This 1-year, two-center hospital-based clinical study aimed to investigate the relationship of blood eosinophil cell counts and/or IgE levels with the clinical outcomes of COPD patients treated with long-acting BDs with or without adjunct ICS.

\section{Materials and methods Study design and population}

This study featured a prospective cohort design. From March 2014 to February 2016, patients with COPD were recruited from the Outpatient Clinics of the Chest Medicine Departments of two medical centers (Far Eastern Memorial Hospital and Changhua Christian Hospital). The inclusion criteria for eligible COPD patients were as follows: basic medical history, physical examination, chest X-ray findings, and lung function data. The inclusion criteria for COPD included chronic airway symptoms such as a productive cough, breathlessness, and/or wheezing and confirmed 
chronic airway obstruction by spirometry, defined as 1) a forced expiratory volume in 1 second $\left(\mathrm{FEV}_{1}\right) /$ forced vital capacity (FVC) of $<70 \%$ and 2 ) a $\mathrm{FEV}_{1}$ of $<80 \%$ of the predicted value. Men and women (aged $>40$ years) who had been diagnosed with COPD more than 6 months prior to screening were enrolled in the study. A smoking history equivalent to $>10$ pack-years was also required. Patients with the following conditions were excluded from the study: a life-threatening COPD acute exacerbation (AE) within the past year; emergency department or hospitalization visit for COPD exacerbation in the 4 weeks prior to the screening period; receipt of a systemic corticosteroid prescription in the month before screening; a history of non-smoking or an equivalent of $<10$ pack-years; a significant asthma and atopy diagnosis without a smoking history; active pulmonary tuberculosis; and/or a clinically significant respiratory tract infection in the 4 weeks before screening. Patients who currently use medications that affect bronchospasms and/or lung functions were also excluded.

Patients initially underwent serum testing for eosinophil counts and $\operatorname{IgE}$ analysis at the time of the initial COPD diagnosis. Eosinophilia and an elevated IgE level were defined as $>3 \%$ and $173 \mathrm{IU} / \mathrm{mL},{ }^{12}$ respectively. The participants were classified into four groups according to these parameters: higher eosinophil count and IgE level (HEE), higher eosinophil count (HEO), higher IgE level (HIE), and lower eosinophil count and IgE level (LEE). The Far Eastern Memorial Hospital and Changhua Christian Hospital Institutional Review Boards approved the collection of anonymized samples for the present study. Ethical approval from the hospitals and informed consent from all study subjects were obtained.

An AE of COPD was defined as a presentation with at least two major symptoms, including increased dyspnea, increased sputum purulence, and increased sputum volume, or one major and one minor symptom (including nasal discharge/congestion, wheeze, sore throat, cough) for at least 2 consecutive days. All chest radiographs were assessed by the investigators (respiratory physicians).

\section{Assessment of efficacy and safety}

During the 52-week treatment follow-up period, patients underwent clinical evaluations, including spirometric lung function tests ( $\mathrm{FEV}_{1}$ and $\mathrm{FVC}$ ) and symptom scoring using the COPD Assessment Test (CAT) to evaluate the intervention. Spirometry testing, CAT, and clinical parameter assessment were performed at the baseline and every 3 months thereafter throughout the study period. Therapies were classified as ICS based or BD based. The primary endpoint was a comparison of lung function at the initial treatment versus that at the end of the study in patients treated with either type of therapy. The secondary endpoints included the frequency of health-related quality of life with CAT scores and AE (COPD deterioration resulting in emergency treatment, hospitalization, or treatment with additional systemic steroid or antibiotic agents). Adverse events were documented using spontaneous reports, patient interviews, and diary entries.

\section{Statistical analysis}

Among patients' demographic and clinical characteristics, age is presented as mean \pm standard deviation (SD) and other categorical variables are summarized as numbers (\%) and were evaluated using the chi-square test. Continuous variables are presented as medians with interquartile ranges (range between the 25th and 75 th percentiles). Continuous variables were analyzed using an analysis of variance with a random-effect model. The Mann-Whitney test was used for comparisons of two independent groups. The KruskalWallis method and Bonferroni post hoc analysis were used for multiple testing. The diagnostic performances of eosinophil cell counts and IgE for COPD were determined using receiver operating characteristic (ROC) curves. The ROC curves for different outcomes were compared using the Hanley and McNeil method. All statistics are two sided, and a $P$-value $<0.05$ was considered to indicate statistical significance. All statistical analyses were performed using SPSS software, version 16.0 (SPSS, Inc., Chicago, IL, USA).

\section{Results}

\section{Baseline demographics and disease characteristics}

A total of 304 patients with COPD were included in the study. The HEE and LEE patient groups were larger $(n=85$ and $n=121$, respectively) than the HEO and HIE groups $(n=51$ and $n=47$, respectively; Table 1). The overall baseline characteristics of the four groups were similar. In all groups, the mean ages ranged from 64 to 68 years $(P=0.136)$, and most patients (91.7\%-95.7\%) were male. Additionally, $12 \%-15 \%$ of patients had a positive BD test, and most patients had a COPD classification of Global Initiative for Chronic Obstructive Lung Disease (GOLD) II or GOLD III. CAT, pulmonary function, medication use, and comorbidity parameters were also similar across the groups $(P \geq 0.066)$. By contrast, the frequency of an AE that required $>1$ hospitalization was higher in the HEE group (18.8\%) than in the 
Table I Baseline demographic characteristics of study subjects with COPD

\begin{tabular}{|c|c|c|c|c|c|}
\hline & HEE $(n=85)$ & HEO $(n=5 I)$ & HIE $(n=47)$ & LEE $(n=121)$ & $P$-value \\
\hline Age, year (mean \pm SD) & $64.3 \pm 18.1$ & $69.5 \pm 19.9$ & $67.8 \pm 18.5$ & $68.2 \pm 21.6$ & 0.136 \\
\hline Sex & & & & & 0.582 \\
\hline Male & $79(92.9 \%)$ & 47 (92.2\%) & 45 (95.7\%) & $111(91.7 \%)$ & \\
\hline Female & $6(7.1 \%)$ & $4(7.8 \%)$ & $2(4.3 \%)$ & $9(7.4 \%)$ & \\
\hline Smoking, pack-years (mean \pm SD) & $25.1 \pm 14.7$ & $26.6 \pm 19.5$ & $24.7 \pm 15.4$ & $26.2 \pm 20.2$ & 0.481 \\
\hline Acute exacerbation ( $>$ I admission) & $16(18.8 \%)$ & $7(13.7 \%)$ & $6(12.8 \%)$ & $13(10.7 \%)$ & $0.043^{*}$ \\
\hline \multicolumn{6}{|l|}{ Lung function test } \\
\hline Bronchodilator test respond $(+)$ & II (I4.8\%) & $6(11.8 \%)$ & $6(12.8 \%)$ & 14 (11.6\%) & 0.144 \\
\hline GOLD I (\%) & $6(7.1)$ & $5(9.8)$ & $5(10.6)$ & $17(14.0)$ & 0.078 \\
\hline GOLD II (\%) & $41(48.2)$ & $24(47.1)$ & $22(46.8)$ & $59(48.8)$ & \\
\hline GOLD III (\%) & $22(25.9)$ & $17(33.3)$ & $14(29.8)$ & $38(31.4)$ & \\
\hline GOLD IV (\%) & $16(18.8)$ & $5(9.8)$ & $6(12.8)$ & $7(5.8)$ & \\
\hline Group A (\%) & $5(5.9)$ & $7(\mid 3.7)$ & $5(10.6)$ & $20(16.5)$ & 0.06 \\
\hline Group B (\%) & $37(43.5)$ & $22(43.1)$ & $19(40.4)$ & $61(50.4)$ & \\
\hline Group C (\%) & $25(29.4)$ & $18(35.3)$ & $19(40.4)$ & $32(26.4)$ & \\
\hline Group D (\%) & $18(21.1)$ & $4(7.8)$ & $4(8.5)$ & $8(6.6)$ & \\
\hline $\mathrm{FEV}_{1}$ (L) (\% of predicted) & $1.24 \pm 0.18(48.7)$ & $1.28 \pm 0.2 \mid(52.5)$ & $1.37 \pm 0.19(58.9)$ & $1.35 \pm 0.24(56.2)$ & 0.117 \\
\hline FVC (L) (\% of predicted) & $2.19 \pm 0.42(49.5)$ & $2.29 \pm 0.52(53.8)$ & $2.40 \pm 0.45(60.6)$ & $2.46 \pm 0.5 \mathrm{I}(62.7)$ & 0.066 \\
\hline $\mathrm{FEV}_{\mathrm{I}} / \mathrm{FVC}$ (\% of predicted) & $50.2 \pm 20.3$ & $49.4 \pm 22.9$ & $51.9 \pm 18.1$ & $51.6 \pm 19.4$ & 0.273 \\
\hline FEV, reversibility (\%) & $6.2 \pm 5.5$ & $8.4 \pm 5.9$ & $6.3 \pm 5.8$ & $7.1 \pm 6.4$ & 0.391 \\
\hline CAT baseline & $17 \pm 9$ & $14 \pm 10$ & $14 \pm 9$ & $18 \pm 9$ & 0.529 \\
\hline \multicolumn{6}{|l|}{ Medications } \\
\hline LABA (\%) & II (I2.9) & $5(9.8)$ & $6(12.8)$ & $18(14.9)$ & 0.214 \\
\hline LAMA (\%) & $19(22.3)$ & $15(29.4)$ & $13(27.7)$ & $32(26.4)$ & \\
\hline LABA/LAMA (\%) & $20(23.5)$ & $12(23.5)$ & $14(29.8)$ & $29(23.9)$ & \\
\hline ICS/LABA (\%) & $14(16.5)$ & $6(11.8)$ & $7(14.8)$ & $19(15.7)$ & \\
\hline ICS/LABA/LAMA (\%) & $21(24.7)$ & $13(25.5)$ & $7(14.8)$ & $23(19.0)$ & \\
\hline \multicolumn{6}{|l|}{ Comorbidity } \\
\hline Hypertension (\%) & $33(39.2)$ & $19(37.2)$ & $17(36.2)$ & $47(38.8)$ & 0.113 \\
\hline Diabetes mellitus (\%) & $14(16.5)$ & $9(17.6)$ & $10(21.2)$ & $17(14.0)$ & \\
\hline Coronary artery disease (\%) & $9(10.6)$ & $8(I 5.7)$ & $4(8.5)$ & $14(11.6)$ & \\
\hline Congestive heart failure (\%) & II (I2.9) & $6(11.8)$ & $7(14.9)$ & $20(16.5)$ & \\
\hline
\end{tabular}

Notes: Continuous variables are presented as mean \pm SD; categorical variables are presented as numbers and percentages. *Significant difference between the four groups: $P<0.05$.

Abbreviations: CAT, COPD Assessment Test; COPD, chronic obstructive pulmonary disease; FEV , forced expiratory volume in I second; FVC, forced vital capacity; GOLD, Global Initiative for Chronic Obstructive Lung Disease; HEE, higher eosinophil count and lgE levels; HEO, higher eosinophil count; HIE, higher IgE level; ICS, inhaled corticosteroids; LABA, long-acting $\beta$-agonist; LAMA, long-acting muscarinic antagonist; LEE, lower eosinophil count and IgE level; SD, standard deviation.

other three groups $(13.7 \%, 12.8 \%$, and $10.7 \%$ in the HEO, HIE, and LEE groups, respectively, $P=0.043$ ).

\section{Treatment outcomes}

Treatment outcomes were evaluated in the three patient groups with high eosinophil cell counts and/or IgE levels. In the HEE group, ICS-based therapy was associated with a significantly greater $\mathrm{FEV}_{1}$ and $\mathrm{FVC}$ and better CAT results, compared to BD-based therapy $(P \leq 0.042)$ (Table 2$)$. Additionally, in this group, ICS-based therapy was associated with a significantly lower incidence of AEs, compared with BD-based therapy (11.7\% vs $24.1 \% ; P<0.008)$. Furthermore, ICS-based therapy yielded significantly better CAT results among patients in the HEO group, compared with BDbased treatment ( 7 vs $13 ; P=0.032$; Table 2 ). However, no significant differences between treatments were observed in terms of pulmonary functions and the frequency of AEs in the HEO group ( $P$-values $\geq 0.072$ ). The outcomes did not differ with respect to ICS-based and BD-based therapies among patients in the HIE group ( $P$-values $\geq 0.129$; Table 2 ).

\section{ROC curve analysis}

The ROC curve analysis indicated that the area under the curve was greatest for patients in the HEE group (0.78) compared to those in the HEO (0.64) and HIE groups (0.69), as well as those in the LEE group (0.533) $(P=0.046$; Figure 1).

\section{Discussion}

COPD is a heterogeneous disorder that encompasses different phenotypes with distinct clinical characteristics. 
Table 2 Treatment effectiveness in COPD patients with allergic phenotypes

\begin{tabular}{|c|c|c|c|c|c|c|}
\hline & HEE $(n=85)$ & $P$-value & HEO $(n=5 I)$ & $P$-value & HIE $(n=47)$ & $P$-value \\
\hline \multicolumn{2}{|c|}{ Lung function FEV $(\mathrm{mL})$} & $<0.008 *$ & & 0.072 & & 0.129 \\
\hline ICS-based therapy ${ }^{\dagger}$ & $132.4 \pm 28.8$ & & $115.5 \pm 30.9$ & & $119.8 \pm 31.4$ & \\
\hline BD-based therapy ${ }^{\dagger}$ & $85.7 \pm 24.2$ & & $96.1 \pm 28.7$ & & $97.4 \pm 32.7$ & \\
\hline \multicolumn{2}{|c|}{ Lung function FVC (mL) } & $<0.007^{*}$ & & 0.141 & & 0.352 \\
\hline ICS-based therapy & $|4| . \mid \pm 39.6$ & & $119.9 \pm 42.3$ & & $123.8 \pm 40.7$ & \\
\hline BD-based therapy & $105.8 \pm 4 \mid .7$ & & $124.6 \pm 39.7$ & & $126.6 \pm 44.1$ & \\
\hline \multicolumn{2}{|c|}{ COPD Assessment Test } & $0.042 *$ & & $0.032 *$ & & 0.416 \\
\hline ICS-based therapy & $8 \pm 5$ & & $7 \pm 6$ & & $9 \pm 7$ & \\
\hline BD-based therapy & $12 \pm 7$ & & $13 \pm 9$ & & $1 \mathrm{II} \pm 8$ & \\
\hline \multicolumn{2}{|c|}{ Acute exacerbation ( $>$ I hospitalization) } & $<0.008 *$ & & 0.245 & & 0.475 \\
\hline ICS-based therapy & $10(11.7 \%)$ & & $7(13.6 \%)$ & & $6(13.4 \%)$ & \\
\hline BD-based therapy & $21(24.1 \%)$ & & $10(19.8 \%)$ & & $10(20.3 \%)$ & \\
\hline
\end{tabular}

Notes: Continuous variables are presented as mean \pm SD; categorical variables are presented as numbers and percentages. *Significant difference between ICS- and BDbased treatment within a given group, $P<0.05$. ${ }^{\dagger}$ ICS-based therapy including ICS/LABA or ICS/LABA/LAMA; BD-based therapy including LABA; LAMA or LABA/LAMA.

Abbreviations: BD, bronchodilator; COPD, chronic obstructive pulmonary disease; FEV eosinophil count and IgE level; HEO, higher eosinophil count; HIE, higher lgE level; ICS, inhaled corticosteroids; LABA, long-acting $\beta$-agonist; LAMA, long-acting muscarinic antagonist.

Traditionally, these different phenotypes have been defined according to pathogenesis, natural history, risk factors, prognosis, and treatment response. Furthermore, this phenotypic diversity may partly explain the variable responses to therapy observed among COPD patients. Therefore, the identification of biomarkers that could be used to guide treatment would yield great clinical benefits. The present study investigated whether the plasma IgE levels and/or eosinophil cell counts could be used as biomarkers to stratify patients with COPD according to predicted responses to ICS-based therapy.

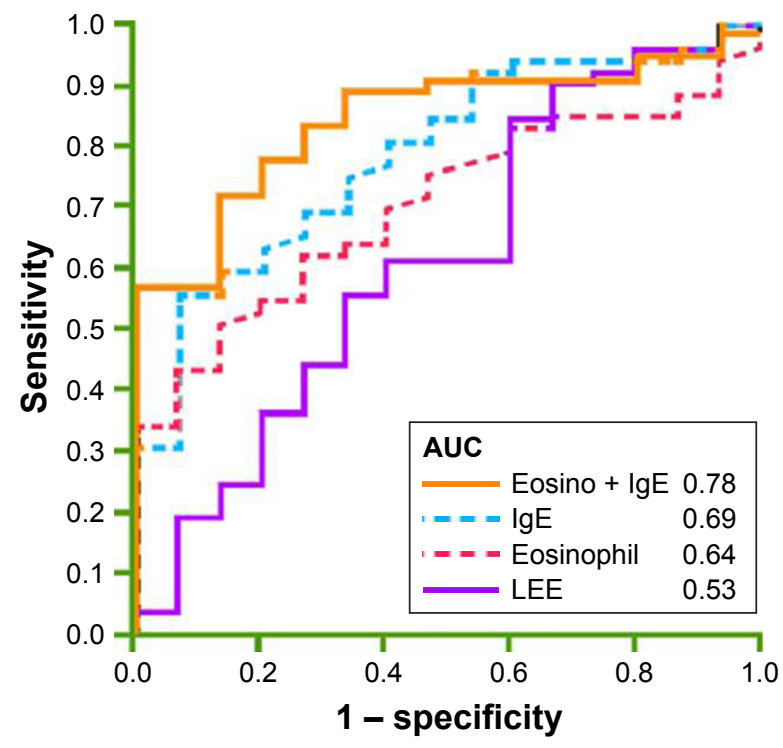

Figure I ROC curves for eosinophil + IgE, IgE, eosinophil, and LEE in patients with chronic obstructive pulmonary disease.

Abbreviations: eosino, eosinophil; IgE, immunoglobulin E; LEE, lower eosinophil and IgE group; ROC, receiver operating characteristic.
The study results indicate that patients with both high plasma IgE levels and eosinophilia have a significantly greater pulmonary response, a reduced risk of $\mathrm{AE}$, and improved CAT scores when treated with a combination of ICS- and BD-based therapy, compared with BD therapy alone. By contrast, patients with either high plasma IgE levels or eosinophilia generally had similar treatment responses, regardless whether ICS were added to BD-based therapy. In addition, ICS therapy did not reduce the risk of AE in these latter two patient populations. ROC curve analysis suggests that the combination of the two biomarkers might better identify patients who would benefit from the addition of ICS to BD therapy, compared with either biomarker alone.

Several previous studies have evaluated the use of eosinophil cell counts as a biomarker of ICS responses in patients with COPD. Leigh et al observed an association of sputum eosinophilia ( $>3 \%$ in induced samples) with significant improvements in the $\mathrm{FEV}_{1}$ and dyspnea following treatment with inhaled budesonide. ${ }^{39}$ Similar findings were reported for prednisone. ${ }^{40}$ Pascoe et al performed a post hoc analysis of two replicate randomized studies that assessed the effectiveness of vilanterol alone or in combination with fluticasone in patients with mild-to-moderate COPD and a history of $\geq 1$ exacerbation in the previous year. ${ }^{33,35}$ The authors compared the rate of exacerbations in patients from the original study, who had baseline blood eosinophil frequencies of $<2 \%$ of $\geq 2 \%$ ( $n=3,177)$. Pascoe et al found that vilanterol plus fluticasone was associated with a significantly greater reduction in the exacerbation rate among patients with blood eosinophil frequencies $\geq 2 \%$, compared with vilanterol alone ( 0.91 vs 
1.28 exacerbation per patient per year; $P<0.0001$ ), but not among patients with blood eosinophil frequencies $<2 \%$ ( 0.79 vs $0.89 ; P=0.2827) .{ }^{33}$ The authors also found no association of blood eosinophil cell counts with improvements in $\mathrm{FEV}_{1}$ or the risk of pneumonia when administering vilanterol plus fluticasone vs vilanterol alone.

Siddiqui et al performed a post hoc analysis of data from the Foster 48-week Trial to Reduce Exacerbations in COPD trial to examine the role of blood eosinophil levels on treatment responses to fluticasone plus beclomethasone vs fluticasone alone. ${ }^{34}$ Patients $(n=1,184)$ were stratified into four quartiles based on their baseline blood eosinophil cell counts $(<110.5 / \mu \mathrm{L}, 110.4-<181.6 / \mu \mathrm{L}, 181.6-<279.8 / \mu \mathrm{L}$, and $\geq 279.8 / \mu \mathrm{L})$. The authors observed greater treatment differences in patients with baseline eosinophil counts $\geq 279.8 / \mu \mathrm{L}$, compared to those with lower eosinophil counts. Furthermore, in the highest eosinophil count group, treatment with fluticasone plus beclomethasone resulted in significantly better improvements in $\mathrm{FEV}_{1}$, COPD exacerbation rate, and changes in St George's Respiratory Questionnaire scores $(P$-values $<0.001)$. The studies by Pascoe et al and Siddiqui et al both support the use of the eosinophil cell count as a predictive biomarker of responses to ICS. By contrast, in our study, only patients with both increased levels of eosinophils and $\mathrm{IgE}$ benefited from the addition of ICS to BD-based therapy. However, neither Pascoe et al nor Siddiqui et al evaluated IgE levels in their patient populations, and therefore it is difficult to directly compare findings between these studies.

Another post hoc analysis evaluated the effectiveness and safety of high- or medium-dose ICS when combined with salmeterol for patients with different blood eosinophil counts. ${ }^{36}$ Cheng and $\operatorname{Lin}^{38}$ used data from a previous prospective randomized study and classified patients $(n=248)$ into higher and lower eosinophil count groups. The authors observed the greatest increase in $\mathrm{FEV}_{1}$ among patients with high eosinophil counts when treated with higher dose fluticasone $(1,000 \mu \mathrm{g} /$ day $)$ plus salmeterol $(P<0.05)$. Additionally, among patients with high eosinophil counts, those who were treated with high-dose fluticasone plus salmeterol therapy experienced greater quality of life improvements (evaluated by the CAT) than those treated with low-dose fluticasone $(500 \mu \mathrm{g} /$ day) plus salmeterol or those with low blood eosinophil counts, regardless of the ICS dose.

By contrast, a prospective study by Roche et al found that administration of a once-daily LABA/long-acting muscarinic antagonist combination therapy comprising indacaterol plus glycopyrronium was similarly, if not more, effective as a twice-daily administration of the LABA/ICS combination of salmeterol plus fluticasone for patients with COPD. ${ }^{37}$ That study compared treatment efficacies according to blood eosinophil levels ( $<2 \%$ and $\geq 2 \%,<3 \%$ and $\geq 3 \%$, and $<5 \%$ and $\geq 5 \%$ ) and absolute blood eosinophil counts ( $\leq 150$ cells $/ \mu \mathrm{L}, 150-<300$ cells $/ \mu \mathrm{L}$, and $\geq 300$ cells $/ \mu \mathrm{L})$. Roche et al found that indacaterol plus glycopyrronium was superior to salmeterol plus fluticasone for the prevention of exacerbations, regardless of the baseline eosinophil level. Moreover, the rate of moderate or severe exacerbation did not increase with increasing blood eosinophil cell levels. Patients in both the $<2 \%$ and $\geq 2 \%$ eosinophil groups who received salmeterol plus fluticasone had a higher incidence of pneumonia when compared with those who received indacaterol plus glycopyrronium. The cross-study differences in findings might reflect differences in the study designs, patient populations, and specific treatment regimens used.

Several limitations of the present study should be considered. This study was not a prospective randomized study, and we did not use specified cutoff values for eosinophil cell counts or IgE levels. It is possible, as observed by Siddiqui et al, that patients with different eosinophil counts and/or IgE levels might have different responses to therapy. Prospective, randomized studies are needed to further investigate the uses of eosinophil cell counts and IgE levels as biomarkers predictive of which patients with COPD would benefit from the addition of ICS to BD therapy.

Finally, the complex and heterogeneous nature of COPD has prompted us to design a novel COPD therapeutic policy that addresses lung function severity, symptoms, serum biomarkers, phenotypes, and comorbidities. The clinical phenotypes should comprise a survey of frequent exacerbators, chronic bronchitis, ACOS, and bronchiectasis-COPD overlay syndrome. Our strategy includes three components. The first addresses an evaluation via the lung function status and symptom severity. The lung function status is determined by GOLD severity (I-IV), and symptom severity is evaluated using modified Medical Research Council (mMRC) or CAT scores. The second involves serum biomarkers, specifically the serum eosinophil frequency and $\operatorname{IgE}$ level. The third combines phenotypes and comorbidities (Figure 2). All suggested medications and comorbidity management methods are included in this COPD therapy strategy. The cutoff values for each parameter are as follows: severe lung function status, $\mathrm{FEV}_{1}<50 \%$ of predicted value; $\mathrm{mMRC}>2$ and CAT score $>10$; and serum eosinophil frequency $>3 \%$ and IgE level $>173 \mathrm{IU} / \mathrm{mL}$. According to our study results, it is most important to use the serum eosinophil and $\operatorname{IgE}$ levels 


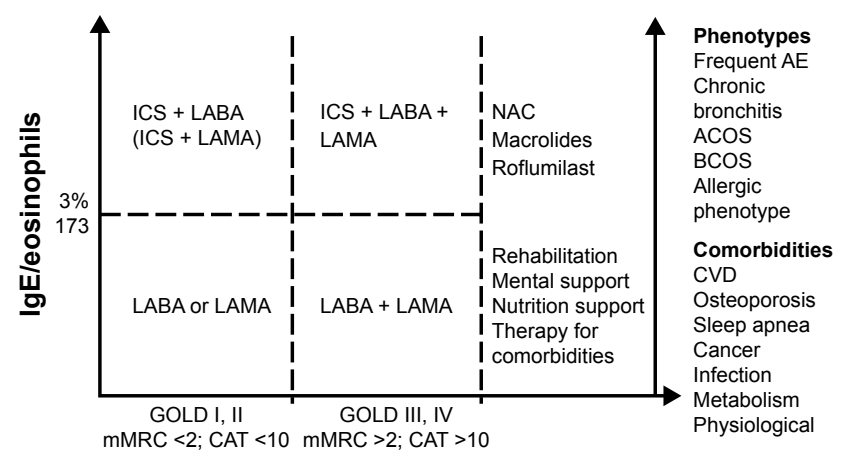

Airway obstruction/symptoms

Figure 2 Chronic obstructive pulmonary disease treatment strategy, including lung function, symptoms, serum biomarkers, phenotypes, and comorbidities.

Abbreviations: ACOS, asthma-COPD overlap syndrome; AE, acute exacerbation; BCOS, bronchiectasis-COPD overlay syndrome; CAT, COPD Assessment Test; CVD, cardiovascular disease; GOLD, Global Initiative for Chronic Obstructive Lung Disease; ICS, inhaled corticosteroids; IgE, immunoglobulin E; LABA, longacting $\beta$-agonist; LAMA, long-acting muscarinic antagonist; mMRC, modified Medical Research Council; NAC, N-acetylcysteine.

as guides for treatment decisions regarding the prescription of ICS therapy for COPD patients.

\section{Conclusion}

The findings of this study support the combined use of blood eosinophil and IgE levels as predictive biomarkers of responses to ICS among patients with COPD. The use of both biomarkers yielded greater improvements in pulmonary function and quality of life and a reduced exacerbation rate. Blood eosinophil and IgE levels could potentially be used to help tailor treatments an optimize outcomes among patients with COPD.

\section{Acknowledgment}

This study was supported by grants from the Far Eastern Memorial Hospital (numbers: FEMH-2016-D-011 and FEMH-2017-C-040).

\section{Author contributions}

All authors contributed toward data analysis, drafting and critically revising the paper and agree to be accountable for all aspects of the work.

\section{Disclosure}

The authors report no conflicts of interest in this work.

\section{References}

1. Celli BR, MacNee W; ATS/ERS Task Force. Standards for the diagnosis and treatment of patients with COPD: a summary of the ATS/ERS position paper. Eur Respir J. 2004;23(6):932-946.

2. Vestbo J, Hurd SS, Agustí AG, et al. Global strategy for the diagnosis, management, and prevention of chronic obstructive pulmonary disease: GOLD executive summary. Am J Respir Crit Care Med. 2013;187(4):347-365.
3. Peces-Barba G, Barberà JA, Agustí A, et al. Guía clínica SEPAR-ALAT de diagnóstico y tratamiento de la EPOC. [Diagnosis and management of chronic obstructive pulmonary disease: joint guidelines of the Spanish Society of Pulmonology and Thoracic Surgery (SEPAR) and the Latin American Thoracic Society (ALAT)]. Arch Bronconeumol. 2008;44(5):271-281. Spanish.

4. Soler-Cataluña JJ, Cosío B, Izquierdo JL, et al. [Consensus document on the overlap phenotype COPD-asthma in COPD]. Arch Bronconeumol. 2012;48(9):331-337. Spanish [with English abstract].

5. Platts-Mills TA. The role of immunoglobulin $\mathrm{E}$ in allergy and asthma. Am J Respir Crit Care Med. 2001;164(8 Pt 2):S1-S5.

6. Han MK, Agusti A, Calverley PM, et al. Chronic obstructive pulmonary disease phenotypes: the future of COPD. Am J Respir Crit Care Med. 2010;182(5):598-604.

7. Miravitlles M, Calle M, Soler-Cataluña JJ. [Clinical phenotypes of COPD: identification, definition and implications for guidelines]. Arch Bronconeumol. 2012;48(3):86-98. Spanish [with English abstract].

8. Kurashima K, Takaku Y, Ohta C, Takayanagi N, Yanagisawa T, Sugita Y. COPD assessment test and severity of airflow limitation in patients with asthma, COPD, and asthma-COPD overlap syndrome. Int $J$ Chron Obstruct Pulmon Dis. 2016;11:479-487.

9. Miravitlles M, Soriano JB, Ancochea J, et al. Characterisation of the overlap COPD-asthma phenotype. Focus on physical activity and health status. Respir Med. 2013;107(7):1053-1060.

10. Hardin M, Silverman EK, Barr RG, et al; COPDGene Investigators. The clinical features of the overlap between COPD and asthma. Respir Res. 2011;12:127.

11. Menezes AMB, Montes de Oca M, Pérez-Padilla R, et al; PLATINO Team. Increased risk of exacerbation and hospitalization in subjects with an overlap phenotype: COPD-asthma. Chest. 2014;145(2):297-304.

12. Kobayashi S, Hanagama M, Yamanda S, Ishida M, Yanai M. Inflammatory biomarkers in asthma-COPD overlap syndrome. Int $J$ Chron Obstruct Pulmon Dis. 2016;11:2117-2123. eCollection 2016.

13. Araújo D, Padrão E, Morais-Almeida $\mathrm{M}$, et al. Asthma-chronic obstructive pulmonary disease overlap syndrome - Literature review and contributions towards a Portuguese consensus. Rev Port Pneumol (2006). 2017;23(2):90-99.

14. Fingleton J, Travers J, Williams M, et al; New Zealand Respiratory Health Survey Study Group. Treatment responsiveness of phenotypes of symptomatic airways obstruction in adults. J Allergy Clin Immunol. 2015;136(3):601-609.

15. Hurst JR. The rhythm of chronic obstructive pulmonary disease exacerbations. J Clin Epidemiol. 2010;63(12):1285-1286.

16. Santibáñez M, Garrastazu R, Ruiz-Nuñez M, et al. Predictors of hospitalized exacerbations and mortality in chronic obstructive pulmonary disease. PLoS One. 2016;11(6): 0158727.

17. Soler-Cataluña JJ, Martínez-García MA, Román Sánchez P, Salcedo E, Navarro M, Ochando R. Severe acute exacerbations and mortality in patients with chronic obstructive pulmonary disease. Thorax. 2005; 60(11):925-931.

18. Bafadhel M, McKenna S, Terry S, et al. Acute exacerbations of chronic obstructive pulmonary disease: identification of biologic clusters and their biomarkers. Am J Respir Crit Care Med. 2011;184(6): $662-671$.

19. McDonald VM, Higgins I, Wood LG, Gibson PG. Multidimensional assessment and tailored interventions for COPD: respiratory utopia or common sense? Thorax. 2013;68(7):691-694.

20. Negewo NA, McDonald VM, Baines KJ, et al. Peripheral blood eosinophils: a surrogate marker for airway eosinophilia in stable COPD. Int J Chron Obstruct Pulmon Dis. 2016;11:1495-1504.

21. Fahy JV, Locksley RM. The airway epithelium as a regulator of Th2 responses in asthma. Am J Respir Crit Care Med. 2011;184(4): 390-392.

22. Global Initiative for Asthma (GINA). Global strategy for asthma management and prevention. NHLBI/WHO workshop report 2002. NHI Publication 02-3659. Available from: http://www.ginasthma.com. Accessed July 19, 2017. 
23. Gartlehner G, Hansen RA, Carson SS, Lohr KN. Efficacy and safety of inhaled corticosteroids in patients with COPD: a systematic review and meta-analysis of health outcomes. Ann Fam Med. 2006;4(3): 253-262.

24. Jones PW, Willits LR, Burge PS, Calverley PM; Inhaled Steroids in Obstructive Lung Disease in Europe study investigators. Disease severity and the effect of fluticasone propionate on chronic obstructive pulmonary disease exacerbations. Eur Respir J. 2003;21(1):68-73.

25. Burge PS, Calverley PM, Jones PW, Spencer S, Anderson JA, Maslen TK. Randomised, double blind, placebo controlled study of fluticasone propionate in patients with moderate to severe chronic obstructive pulmonary disease: the ISOLDE trial. BMJ. 2000;320(7245): 1297-1303.

26. Vestbo J, Sørensen T, Lange P, Brix A, Torre P, Viskum K. Long-term effect of inhaled budesonide in mild and moderate chronic obstructive pulmonary disease: a randomised controlled trial. Lancet. 1999; 353(9167):1819-1823.

27. Kew KM, Seniukovich A. Inhaled steroids and risk of pneumonia for chronic obstructive pulmonary disease. Cochrane Database Syst Rev. 2014;(3):CD010115.

28. Vestbo J, Vogelmeier C, Small M, Higgins V. Understanding the GOLD 2011 Strategy as applied to a real-world COPD population. Respir Med. 2014;108(5):729-736.

29. Price D, West D, Brusselle G, et al. Management of COPD in the UK primary-care setting: an analysis of real-life prescribing patterns. Int $J$ Chron Obstruct Pulmon Dis. 2014;9:889-904.

30. Miravitlles M, Soler-Cataluña JJ, Calle M, Soriano JB. Treatment of COPD by clinical phenotypes: putting old evidence into clinical practice. Eur Respir J. 2013;41(6):1252-1256.

31. Rennard SI, Calverley PM, Goehring UM, Bredenbröker D, Martinez FJ. Reduction of exacerbations by the PDE4 inhibitor roflumilast - the importance of defining different subsets of patients with COPD. Respir Res. 2011;12:18.
32. Siva R, Green RH, Brightling CE, et al. Eosinophilic airway inflammation and exacerbations of COPD: a randomised controlled trial. Eur Respir J. 2007;29(5):906-913.

33. Pascoe S, Locantore N, Dransfield MT, Barnes NC, Pavord ID. Blood eosinophil counts, exacerbations, and response to the addition of inhaled fluticasone furoate to vilanterol in patients with chronic obstructive pulmonary disease: a secondary analysis of data from two parallel randomised controlled trials. Lancet Respir Med. 2015;3(6):435-442.

34. Siddiqui SH, Guasconi A, Vestbo J, et al. Blood eosinophils: a biomarker of response to extrafine beclomethasone/formoterol in chronic obstructive pulmonary disease. Am J Respir Crit Care Med. 2015; 192(4):523-525.

35. Dransfield MT, Bourbeau J, Jones PW, et al. Once-daily inhaled fluticasone furoate and vilanterol versus vilanterol only for prevention of exacerbations of COPD: two replicate double-blind, parallel-group, randomised controlled trials. Lancet Respir Med. 2013;1(3):210-223.

36. Lee SY, Park HY, Kim EK, et al. Combination therapy of inhaled steroids and long-acting beta2-agonists in asthma-COPD overlap syndrome. Int J Chron Obstruct Pulmon Dis. 2016;11:2797-2803. eCollection 2016.

37. Roche N, Chapman KR, Vogelmeier CF, et al. Reply to correspondence letter regarding "Blood eosinophils and response to maintenance COPD treatment: data from the FLAME trial". Am J Respir Crit Care Med. Epub 2017 June 26.

38. Cheng SL, Lin CH. Effectiveness using higher inhaled corticosteroid dosage in patients with COPD by different blood eosinophilic counts. Int J Chron Obstruct Pulmon Dis. 2016;11:2341-2348.

39. Leigh R, Pizzichini MM, Morris MM, Maltais F, Hargreave FE, Pizzichini E. Stable COPD: predicting benefit from high-dose inhaled corticosteroid treatment. Eur Respir J. 2006;27(5):964-971.

40. Brightling CE, Monteiro W, Ward R, et al. Sputum eosinophilia and shortterm response to prednisolone in chronic obstructive pulmonary disease: a randomised controlled trial. Lancet. 2000;356(9240):1480-1485.
International Journal of COPD

\section{Publish your work in this journal}

The International Journal of COPD is an international, peer-reviewed journal of therapeutics and pharmacology focusing on concise rapid reporting of clinical studies and reviews in COPD. Special focus is given to the pathophysiological processes underlying the disease, intervention programs, patient focused education, and self management protocols.

\section{Dovepress}

This journal is indexed on PubMed Central, MedLine and CAS. The manuscript management system is completely online and includes a very quick and fair peer-review system, which is all easy to use. Visit http://www.dovepress.com/testimonials.php to read real quotes from published authors. 